\title{
Osteonecrosis of the Jaw Beyond Bisphosphonates: Are There Any Unknown Local Risk Factors?
}

This article was published in the following Dove Press journal: Clinical, Cosmetic and Investigational Dentistry

\author{
Johann Lechner $\mathbb{D}^{\prime}$ \\ Volker von Baehr ${ }^{2}$ \\ Bernd Zimmermann ${ }^{3}$ \\ 'Clinic for Integrative Dentistry, Munich, \\ Germany; ${ }^{2}$ Department of Immunology \\ and Allergology, Institute for Medical \\ Diagnostics, Berlin, Germany; ${ }^{3} \mathrm{QINNO}$, \\ Wessling, Germany
}

Introduction: Bisphosphonate (BP)-related osteonecrosis of the jaw (BRONJ) is a complication of intravenous (IV) BP therapy. BP therapy locally affects the dentoalveolar area, while systemic effects are associated with parenteral/IV BP use. Despite numerous publications, the pathogenesis of BRONJ is not fully understood, as only some patients receiving IV BPs develop BRONJ.

Purpose: Can impaired bone remodeling (found in aseptic-ischemic osteonecrosis of the jaw $[\mathrm{AIOJ}]$, bone marrow defects [BMD], or fatty-degenerative osteonecrosis of the jaw [FDOJ]) represent a risk factor for BRONJ formation?

Patients and Methods: A literature search clarified the relationship between AIOJ, BMD, FDOJ, and BRONJ, in which common characteristics related to signal cascades, pathohistology, and diagnostics are explored and compared. A case description examining non-exposed BRONJ is presented.

Discussion: Non-exposed BRONJ variants may represent one stage in undetected BMD development, and progression to BRONJ results from BPs.

Conclusion: Unresolved wound healing at extraction sites, where wisdom teeth have been removed for example, may contribute to the pathogenesis of BRONJ. With IV BP administration, persisting $\mathrm{AIOJ} / \mathrm{BMD} / \mathrm{FDOJ}$ areas may be behind BRONJ development. Therapeutic recommendations include IV BP administration following AIOJ/BMD/FDOJ diagnosis and surgical removal of ischemic areas. BPs should not be regarded as the only cause of osteonecrosis.

Keywords: bisphosphonates, bone marrow defects, osteonecrosis of the jaw, RANTES/ CCL5, ultrasound sonography

\section{Introduction}

Recent literature reviews suggest that bisphosphonates (BPs) may contribute to the growing number of cases of osteonecrosis involving the maxilla and mandible that are associated with the pathogenesis of BP-related osteonecrosis of the jaw (BRONJ). ${ }^{1}$ In the discussion concerning BRONJ, a distinction must be made between diseases featuring reduced osseous mineral content, which may be counteracted by BPs (such as those occurring during menopause or in cases of osteoporosis), and cases that present with indications for BPs (such as tumors). BPs have been used in the treatment of multiple myeloma, breast cancer, prostate cancer, and other tumors. In patients with metastatic breast cancer, the bones are affected in around two-thirds of cases. To protect patients from bone fractures and to reduce
Correspondence: Johann Lechner

Gruenwalder Str. I0A, Munich 8I547,

Germany

Tel +49-89-6970129

Fax +49-89-6925830

Email drlechner@aol.com

Clinical, Cosmetic and Investigational Dentistry 2021:13 2|-37 
pain, patients are often prescribed BPs or a special antibody that prevents the breakdown of, and subsequently stabilizes, affected bone. BRONJ is a newly emerging problem that is recognized as a serious complication of BP therapy, primarily following intravenous (IV) administration. $^{2}$

The concern is that BPs affect the natural remodeling of bone tissues and delay the breakdown of older bone structures. BPs are potent inhibitors of bone resorption and have a chronic effect over a half-life of at least 5 years, possibly exerting their effects for more than 10 years. BRONJ is a seemingly "growing epidemic" associated with osteonecrosis of the jawbone (ONJ). ${ }^{3-5}$ The long-term effects of oncological-related BP treatment on alveolar bone quality include the impact on BP-induced overexpression of alveolar bone remodeling. There are increased osteosclerotic properties in the alveolar bone that are associated with significantly greater bone volume and higher bone density. ${ }^{6,7}$ The risk of BP therapy is divided into two categories: local and systemic risk factors; thus, a distinction must be made between oral and IV administration. Local oral risk factors for BRONJ in cancer patients include dentoalveolar surgery, dental extraction, and dental implant insertion. ${ }^{8}$ Periodontal infections also significantly increase the risk of BRONJ in cancer patients. ${ }^{9}$ In addition, there is a significant correlation between the use of removable prostheses, the administration of high-dose IV BPs, and an increased risk of BRONJ. ${ }^{10}$ In patients receiving oral BP therapy for the treatment of osteoporosis, the prevalence of BRONJ only increased $0.21 \%$ from close to $0 \%$. Systemically, however, there is a much higher risk associated with the IV injection of BPs. This is closely related to the frequent use of BPs in cancer patients who receive a significantly higher total dose over a longer duration. ${ }^{11}$ The mean and minimum time for the development of ONJ is 1.8 years and 10 months, respectively. ${ }^{12}$ The risk of BRONJ in cancer patients exposed to BP therapy is from 50-100 times higher than in cancer patients treated with a placebo. The BRONJ risk for the RANKL inhibitor denosumab was between $0.7 \%$ and $1.9 \%{ }^{13,14}$ The risk of ONJ in cancer patients treated with high doses of IV BPs appears to be significantly higher: in the range of $1-10$ per 100 patients (depending on therapy duration). ${ }^{15} \mathrm{~A}$ recent review reported a wide-ranging BRONJ incidence of $0-27.5 \%$ that was associated with the IV administration of BPs, with an average incidence of $7 \% .{ }^{16}$ The cumulative frequency varied from $0.8-12.0 \%$ and was estimated to be up to $30.0 \%$ in some reports. ${ }^{17,18}$ Despite numerous publications on the subject, the overall pathogenesis of BRONJ does not yet appear to be fully understood. In particular, the reasons why only a subset of patients $(<30 \%)$ receiving IV BPs develop BRONJ remain unclear. Although most patients that develop BRONJ have a history of tooth extraction or injury, these factors do not fully explain the occurrence of BRONJ. ${ }^{8}$ The development of BRONJ in edentulous areas in patients with no apparent history of injury suggests that pre-existing conditions, such as subclinical infections or potentially necrotic areas of the jawbone, may contribute to the conditions that lead to the development of BRONJ.

\section{Research Question}

Why does BRONJ develop in up to $30 \%$ of individuals following IV BP therapy and not the remaining $70 \%$ ? This review raises the question of whether little-known or difficult-to-identify, pre-existing, impaired bone remodeling, such as that occurring in aseptic-ischemic osteonecrosis of the jaw (AIOJ), bone marrow defects (BMD), or fattydegenerative osteonecrosis of the jawbone (FDOJ), represents a local risk factor in the development of BRONJ.

\section{Materials and Methods}

There is still a limited scientific understanding of the relationship between ONJ and BPs. ${ }^{19}$ In order to clarify the research question and present the background and specific common characteristics of AIOJ/BMD/FDOJ and BRONJ, an extensive literature search was carried out in PubMed Central. In the literature, the terms "asepticischemic osteonecrosis of the jaw" (AIOJ), 'bone marrow defects' (BMD), and "fatty-degenerative osteonecrosis of the jawbone" (FDOJ) are used to describe an intramedullary phenomenon with the same pathogenesis, morphology, and pathohistology.

The American Association of Oral and Maxillofacial Surgeons published four staging criteria ("at risk", Stage $0-3) .{ }^{20}$ Stage 0 is of particular interest in our research as it refers to patients with "no clinical evidence of exposed bone, but presence of non-specific symptoms or clinical and/or radiographic abnormalities". The discussion concerning BRONJ is complicated by the fact that there are two clinical forms of BRONJ. The first presents as exposed bone in the maxillofacial region with clinically recognizable necrotic bone that is visibly exposed through the oral mucosa or facial skin, and present for more than 8 weeks, which is referred to as so-called exposed BRONJ. ${ }^{15}$ The second form of BRONJ is particularly interesting for our investigation; it was recently 
emphasized that BRONJ does not always appear with necrotic bone visible through a breech in the oral mucosa. $^{21}$ This form is referred to as "non-exposed BRONJ" (NE-BRONJ). In the absence of exposed bone, it is characterized by clinical features associated with the jaw, such as unexplained jawbone pain, fistulas/sinus tracts, loose teeth, and swelling. ${ }^{22,23}$ Diagnosing NEBRONJ is difficult, as other common jawbone diseases, such as odontogenic infections, may cause similar symptoms and must be excluded. The non-exposed variant may comprise up to one third of all BRONJ cases and is thus not uncommon; ${ }^{24}$ however, this previously underestimated NE-BRONJ is difficult to accurately diagnose. Recently published papers emphasize that NE-BRONJ has received little attention so far and does not fulfill the current definition of BRONJ. ${ }^{25}$ Nevertheless, NE-BRONJ belongs to the same disease as exposed BRONJ and should be identified as part of the full spectrum of BRONJ (see the section titled, "Case descriptions of $\mathrm{AIOJ} / \mathrm{BMD} / \mathrm{FDOJ}$, nonexposed BRONJ, and Actinomyces colonization"). ${ }^{26}$

\section{Bisphosphonates and Antitumor Therapy}

Our investigation requires the identification of the basic immune mechanisms associated with BP administration. Specifically, which mechanism is behind the anti-tumor activity of BPs in cancer patients?

\section{Bisphosphonates and Mesenchymal Stem Cells}

Various studies postulate that BPs change the bone microenvironment around cancer cells, which may prevent cancer cell survival and disease recurrence. ${ }^{27}$ BPs may also reduce the appearance of disseminated tumor cells. The formation of metastases is complex; mesenchymal stem cells (MSCs) are predominantly found in the bone marrow. ${ }^{28}$ MSCs may contribute to the formation of metastases through various mechanisms: (1) MSCs are recruited to develop breast tumors where they can enhance the metastatic potential of weakly tumorigenic breast cancer cells; ${ }^{29}$ (2) MSCs and other bone marrow cells may form a premetastatic niche within the specific tissues to which tumor cells metastasize; ${ }^{30}$ and (3) MSCs are able to maintain the growth and survival of cancer cells in the bone microenvironment where they may contribute to the formation of niches for dormant micrometastases that can later form distant metastases. BPs significantly reduce the ability of MSCs to migrate, thereby reducing the growth and survival of cancer cells. ${ }^{31}$ Thus, the effects of BPs on MSCs in the bone marrow microenvironment contribute to anti-tumor activity by affecting the ability of MSCs to migrate and develop tumors in pre-metastatic niches. BPs disrupt the interaction between MSCs and breast cancer cells within the bone microenvironment, where BPs may also directly inhibit breast cancer cell growth.

\section{Bisphosphonates and Antiangiogenesis}

The antiangiogenic effect of BP administration in tumor patients also plays a role in therapy. ${ }^{32}$ When administered systemically, BPs effectively inhibit angiogenesis. The pronounced antiangiogenic properties of BPs enhance their effectiveness in the treatment of malignant bone diseases. In addition to suppressing RANTES/CCL5 (R/ C) expression in MSCs, BP administration plays a role in the treatment of tumor patients. ${ }^{33}$ Similar to exogenous glucocorticoids and estrogen, ${ }^{34}$ BPs are ischemic and hypoxia-related stressors of bone health that alter jawbone metabolism, thus leading to osteonecrosis. While tumor-associated BP therapy is currently the "heavy weight" for bone health, it may accelerate existing, chronic pathophysiological events within the microcirculation of bone marrow compartments in the jaw. BRONJ development is often characterized by a slow start and usually presents with infarcts and thrombosis of small vascular sections of the supplying artery within the medullary canal; these features also correspond to $\mathrm{AIOJ} / \mathrm{BMD} / \mathrm{FDOJ}$. Myeloid elements (including fat marrow) liquefy and cancellous trabeculae are resorbed, so that individual bone spaces merge and gradually create larger cavities.

\section{Osteoimmunological Parameters of AlOJ/ BMD/FDOJ and BRONJ with the Same Impact in Response to BPs}

If we compare the findings in the sections titled, "Bisphosphonates and mesenchymal stem cells" and "Bisphosphonates and antiangiogenesis" to pre-existing AIOJ/BMD/FDOJ, several strikingly common characteristics shared by BRONJ and AIOJ/BMD/FDOJ can be observed that help to answer our research question. In the sections following "Bisphosphonates and antitumor therapy", we present the foundations for the development of AIOJ/BMD/FDOJ and draw similarities with the development of BRONJ. 


\section{RANTES/CCL5: Overexpression as a Common Osteoimmunological Characteristic of BRONJ and AIOJ/BMD/FDOJ}

The key function of proinflammatory chemokines $\mathrm{R} / \mathrm{C}$ in the formation of breast cancer and its metastasis, as well as a possible connection with the intramedullary signaling of $\mathrm{R} / \mathrm{C}$ overexpression from AIOJ/BMD/FDOJ areas, has been pointed out in previous studies. ${ }^{35,36}$ The conspicuous overexpression of $\mathrm{R} / \mathrm{C}$ in little-known BMDs, as found in AIOJ/BMD/FDOJ, has been reported. ${ }^{37,38} \mathrm{R} / \mathrm{C}$ overexpression is a regulator of healthy bone metabolism in bone needing repair. The starting point for a typical $\mathrm{AIOJ} / \mathrm{BMD} / \mathrm{FDOJ}$ BMDs is the expression of $\mathrm{R} / \mathrm{C}$ and its chemokine receptors (CCR5) in both osteoblasts (OBs) and osteoclasts (OCs). Ligands (CCL5) and receptors (CCR5) simultaneously activate autocrine and paracrine mechanisms in the bone. ${ }^{39}$ One study examined the effects of BPs on human primary OBs and was able to show that the overexpression of proinflammatory $\mathrm{R} / \mathrm{C}$ from BP-treated OBs also occurs in areas affected by BRONJ. ${ }^{40}$ The secretion of proinflammatory cytokines interleukin (IL)-8 and R/C increased after 14 days of treatment with the highest dose of BPs. ${ }^{40}$ The complexity of cytokine control becomes clear at this point. In contrast to the tumor, where BPs in the MSCs reduce R/C expression to such an extent that metastasis is prevented, $\mathrm{R} / \mathrm{C}$ expression is increased by BPs in OBs. If $\mathrm{AIOJ} / \mathrm{BMD} /$ FDOJ is already present, it may be assumed that the associated increased $\mathrm{R} / \mathrm{C}$ secretion is thus further increased by BPs. Specifically, NE-BRONJ may develop as BPs increase the expression of IL- 8 and $\mathrm{R} / \mathrm{C} .{ }^{41}$ Other researchers have confirmed increases in the secretion of proinflammatory IL-8 and R/C from BP-treated OBs. ${ }^{42}$ Combined with the lower proliferation rate of OBs and a decrease in their differentiation, higher doses or accumulations of BPs cause undesirable local changes in the bone by increasing the secretion of IL- 8 and $\mathrm{R} / \mathrm{C}$ from OBs. If these findings are applied to BP administration in the context of a chronic, pre-existing AIOJ/BMD/FDOJ area, then such areas may be expected to exhibit increased $\mathrm{R} / \mathrm{C}$ secretion in response to BPs. This increase may result from the inhibition of OC activity, leading to the development of BRONJ. Figure 1 summarizes the effects of BP administration on the pre-existing physiological derailments associated with tumor and osteoporosis development.

\section{Ischemia as a Common Osteoimmunological Characteristic of BRONJ and AIOJ/BMD/FDOJ}

In the literature, the vascular composition of $\mathrm{AIOJ} / \mathrm{BMD} /$ FDOJ is characterized by the fact that blood flow in the medullary canal is impaired by micro-infarcts, which leads to chronic marrow ischemia. ${ }^{43}$ BRONJ also shows reduced vascularization in the medullary canal. ${ }^{44}$ Several publications have shown that ischemic bone diseases such as $\mathrm{AIOJ} / \mathrm{BMD} / \mathrm{FDOJ}$ and BRONJ are of multifactorial origin and emphasize the "multiple stroke model" as the cause of ischemic bone diseases. ${ }^{45,46}$ In the orthopedic literature, intensive research conducted on the development of ischemic bone disease in the early stages of the disease

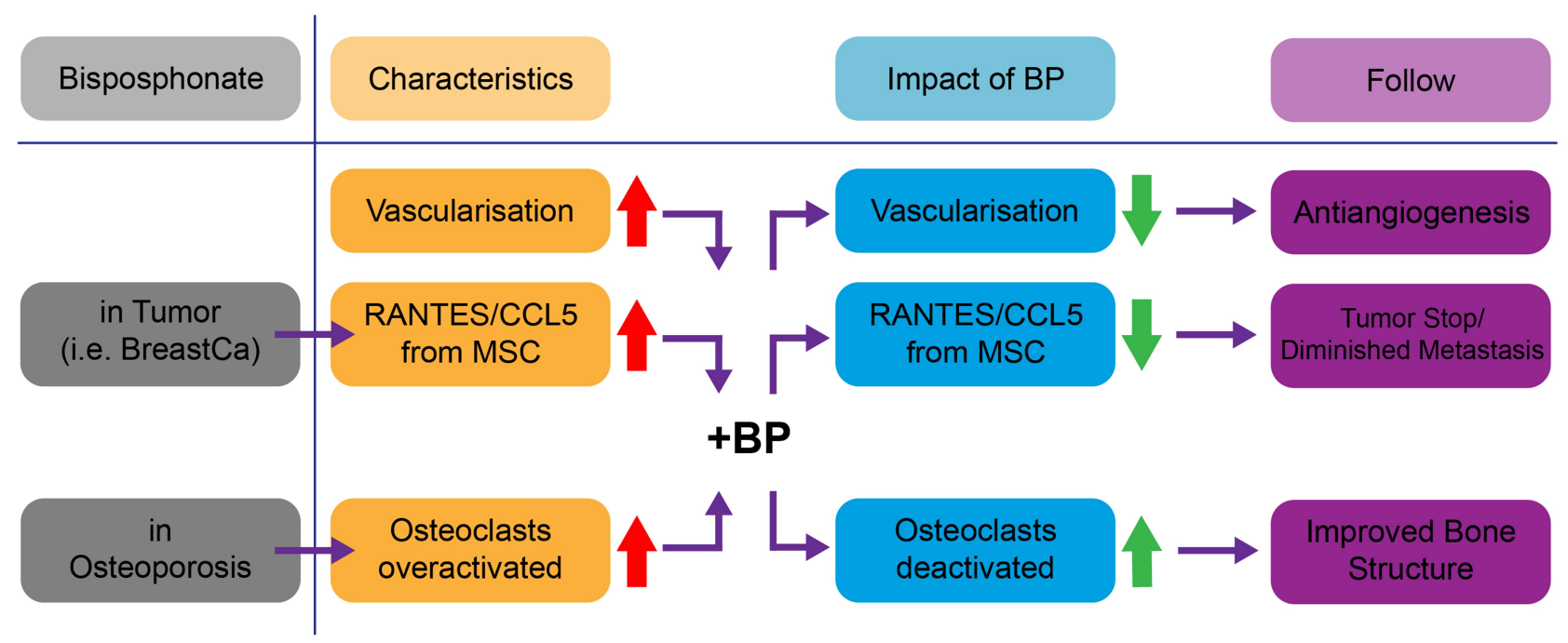

Figure I Comparison of the effects of BP administration (+BP) in the context of a tumor (upper part of Figure I) and pre-existing osteoporosis (lower part of Figure I). Legend: The red arrows indicate overactivity; the green arrows show reversal following BP administration. 
process is presented. ${ }^{47}$ Our aim here is to apply this knowledge not only to extreme forms of the disease, such as osteoradionecrosis and BRONJ, but also to chronic, subclinical, and ischemic forms such as bone marrow edema and AIOJ/BMD/FDOJ, which often progress asymptomatically. Many of these forms are manifestations of both local and systemic risk factors that compromise circulation in the bone marrow, and may also impact on the homeostasis of bone resorption and formation, in addition to BP therapy. The importance of this multifactorial exposure to risk factors for ischemia and the associated causal genetics that are very similar to those in cases of AIOJ/BMD/FDOJ - is shown by observing how bone that is exposed to BPs demonstrates minimal OC activity, followed by the deposition of newly formed, thicker bone with reduced vascular supply. ${ }^{48}$ The resulting mosaic-like pattern of bone remodeling is strikingly similar to that found in Paget's disease, which tends to be associated with the development of osteomyelitis. ${ }^{49}$ Similar to AIOJ/BMD/FDOJ, the remodeling induced by BPs leaves cavities, otherwise known as "cavitations", which leads to both necrosis and - unlike that which is found in $\mathrm{AIOJ} / \mathrm{BMD} / \mathrm{FDOJ}$ - subsequent infection by colonizing bacteria. Many patients with AIOJ/BMD/ FDOJ have inherited prothrombotic tendencies, which is comparable to what is found in patients with idiopathic osteonecrosis of the femoral head (Paget's disease) and includes thrombophilia and hypofibrinolysis. ${ }^{50-52}$ Although a consensus has been reached that ischemic marrow edema is not part of the pathogenesis of BRONJ, ${ }^{53}$ it is regarded as a typical characteristic of $\mathrm{AIOJ} / \mathrm{BMD} / \mathrm{FDOJ}$, serving as a precursor to BRONJ development. Systemic antibiotic therapy has limited access to these avascular zones and surgical debridement is usually necessary.

\section{Osteoblast Activation as a Common Osteoimmunological Characteristic of BRONJ and AIOJ/BMD/FDOJ}

The initial OB situation found in AIOJ/BMD/FDOJ is highly characteristic; under pathological conditions, OBs express R/C chemokines in a non-physiological manner. ${ }^{54,55}$ The increasing frequency of ONJ and its possible association with high cumulative doses of BPs was investigated in one study, which concluded that high doses of BPs had both OC and OB effects, and thus bone remodeling was inhibited in vivo. ${ }^{56}$ Other researchers have examined the proliferation, viability, expression, and secretion of bone markers and cytokines/chemokines from primary OBs following exposure to BPs. ${ }^{42}$ Increased concentrations of proinflammatory cytokines were found in response to BPs. Similarly, increased $\mathrm{R} / \mathrm{C}$ expression is present in AIOJ/BMD/FDOJ. Following treatment with the highest dose of BPs, the secretions of proinflammatory cytokines IL-8 $(P<0.001)$ and $\mathrm{R} / \mathrm{C} \quad(P<0.001)$ were significantly increased after 14 days. In addition, the secretion of proinflammatory $\mathrm{R} / \mathrm{C}$ from OBs exposed to BPs increased. It has also been determined that $\mathrm{R} / \mathrm{C}$ plays a role in the etiology of the osteolytic changes that are present in AIOJ/BMD/ FDOJ. ${ }^{37,57}$ The aim of another study was to investigate the effect of BPs on human OBs in vitro, while considering RANKL and osteoprotegerin (OPG), both of which mediate OC differentiation. ${ }^{40}$ OPG increased significantly in the group that received BPs at a dose of $10 \mu \mathrm{M}$, while RANKL expression decreased significantly with different concentrations of BPs. In summary, exposure to various BP concentrations had a positive effect on $\mathrm{OB}$ differentiation, but did not affect proliferation. In contrast, the BP-associated changes in RANKL and OPG production contributed to the suppression of osteoclastic bone resorption. Excess R/C leads to OC inhibition which, in our model, also leads to a disturbance in RANK/RANKL homeostasis (see Figure 2). The chain of reactions that arise from pre-existing $\mathrm{AIOJ} / \mathrm{BMD} / \mathrm{FDOJ}$ and $\mathrm{BP}$ administration result in the development of BRONJ in response to the subsequent $\mathrm{OB}$ depression; it also leads to increased OC apoptosis. In addition, bone densification takes place following BP administration as a result of increased OB activity. As such, osteonecrosis occurs in the jawbone when BPs are used parenterally. The reasons for these different reactions to BPs have not yet been clarified.

\section{Osteoclast Deactivation as a Common Osteoimmunological Characteristic of BRONJ and AIOJ/BMD/FDOJ}

The first step in tumor necrosis factor alpha (TNF-a)induced $\mathrm{OC}$ genesis occurs in the bone marrow. ${ }^{58}$ Although mature OCs erode the resorption of the bone as a focal point over the course of months to years, the lifespan of individual OCs is only a few weeks. Thus, mature OCs must be constantly replaced. With respect to OC formation, TNF-a directly stimulates the formation of mature OCs, ${ }^{59,60}$ and supports and promotes the survival of mature OCs. ${ }^{61}$ TNF-a increases the survival time of OCs to extend the duration of bone resorption. In the early stages of $\mathrm{AIOJ} / \mathrm{BMD} / \mathrm{FDOJ}$, the situation for OCs is highly contradictory: the extremely low TNF-a values found in areas of $\mathrm{AIOJ} / \mathrm{BMD} / \mathrm{FDOJ}$ - as compared to the 


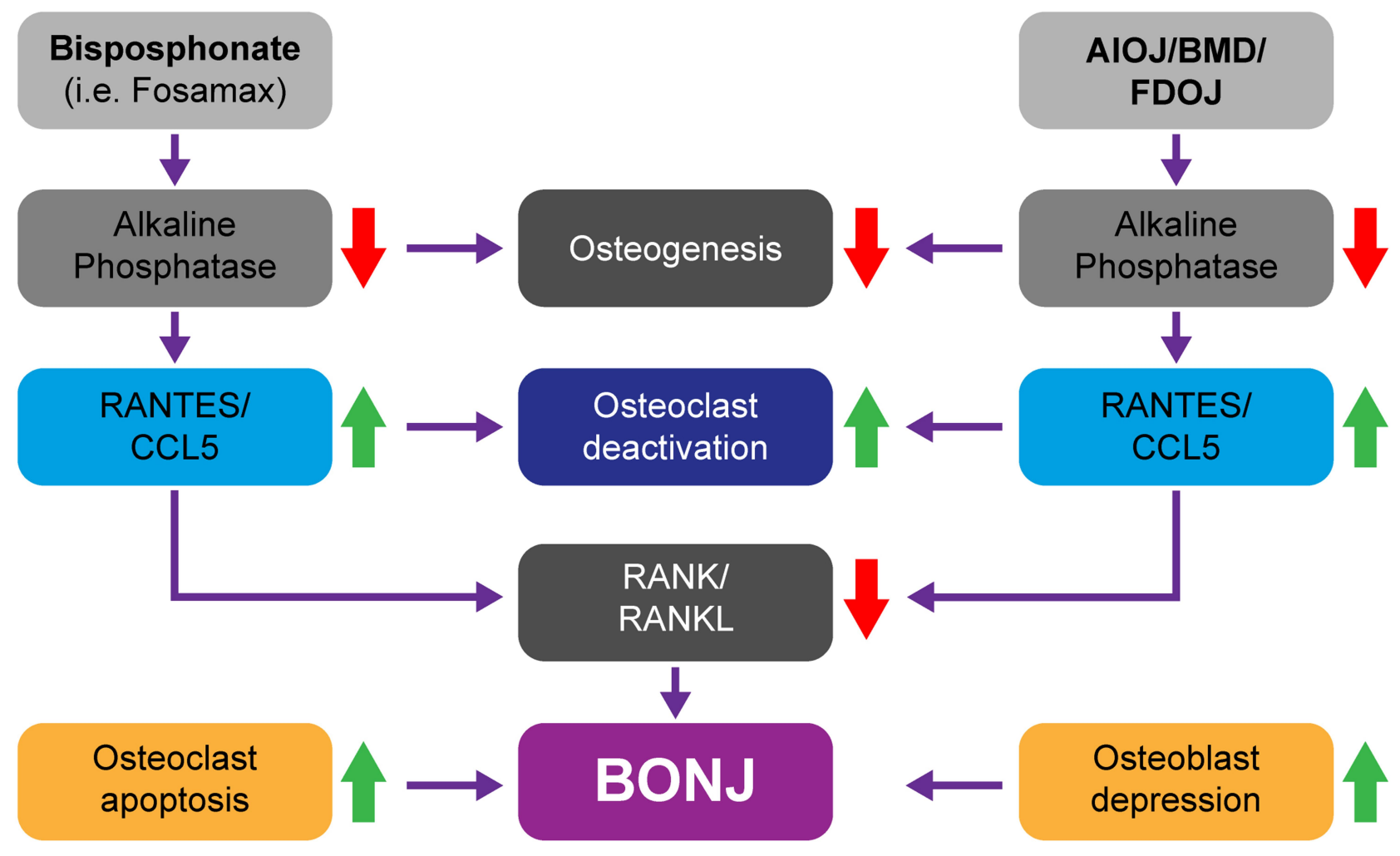

Figure 2 The effects of BP administration and the characteristics of AIOJ/BMD/FDOJ both include depressed alkaline phosphatase (AP) activity with subsequent R/C overexpression. On the one hand, this leads to $O C$ inhibition and, on the other, to RANK/RANKL deactivation, which subsequently causes increased OC apoptosis and depressed $O B$ activity resulting in BRONJ development. Legend: The red arrows indicate deactivation; the green arrows show a reversal of the effect following BP administration.

values in healthy jawbone samples (as documented in our previous studies) - indicate that any "inflammatory erosion" due to TNF-a supported OC formation is unlikely. Due to reduced TNF-a activation, OC formation in AIOJ/ BMD/FDOJ is inhibited, which results in a fattydegenerative morphology. ${ }^{62}$

In the same way, BPs inhibit the ability of OCs to resorb bone. They do so by suppressing farnesyl diphosphate synthetase activity, which inhibits OC recruitment and impacts the life expectancy of OCs through increased apoptosis. Where the OC function is excessively inhibited, dying OCs will not be replaced, and the capillary network of the bone will not be maintained, which leads to BRONJ. ${ }^{19}$ The ability of BPs to regulate bone turnover by suppressing OC activity has led to its widespread use in the treatment of osteoporosis, Paget's disease, humoral hypercalcemia, and in tumors metastasizing to bone. ${ }^{17,63}$ Several studies have shown the effectiveness of BPs in suppressing OC activity in arthritic bone erosions, which was comparable to the effects of OPG injections. ${ }^{64}$

\section{Alkaline Phosphatase Reduction as a Common Osteoimmunological Characteristic of BRONJ and AIOJ/BMD/FDOJ}

The initial alkaline phosphatase (AP) situation in AIOJ/ $\mathrm{BMD} / \mathrm{FDOJ}$ is as follows: $\mathrm{AP}$ has an optimum $\mathrm{pH}$ in the alkaline range. The $\mathrm{pH}$ level of AIOJ/BMD/FDOJ areas, however, is reduced as a consequence of the proinflammatory characteristics of $\mathrm{R} / \mathrm{C}$ overexpression, resulting in a chronic inflammatory state. AP activity is thus inhibited within the increasingly acidic environment of such areas. Furthermore, BPs increase R/C secretion from OBs, and the acidity of areas affected by AIOJ/BMD/FDOJ, together with an excess of $\mathrm{R} / \mathrm{C}$, leads to $\mathrm{OC}$ inhibition. ${ }^{65}$ At the same time, there is also reduced osteogenesis due to the suppression of AP activity, ${ }^{66}$ as well as the overexpression of $\mathrm{R} / \mathrm{C}$ that is present in $\mathrm{AIOJ} / \mathrm{BMD} / \mathrm{FDOJ}$ areas and also caused by BP administration. In our model, these two factors led to OC inhibition via disturbed RANK//RANKL homeostasis. In addition, depressed OB activity and increased OC apoptosis result in BRONJ development. While the skeletal bone consolidation that results from 
$\mathrm{BP}$ administration occurs in response to increased $\mathrm{OB}$ activity, BRONJ develops in the jawbone when BP is administered parenterally. The reasons for these different responses to BPs have not yet been clarified. If we apply these considerations to an existing AIOJ/BMD/FDOJ area (as shown in Figure 2), then BRONJ and AIOJ/BMD/ FDOJ both show suppressed AP activity with subsequent $\mathrm{R} / \mathrm{C}$ overexpression. ${ }^{67}$ This leads to $\mathrm{OC}$ inhibition and RANK/RANKL deactivation and, subsequently, increased OC apoptosis. Decreased OB activity may ultimately lead to the development of exposed BRONJ.

\section{Osteoimmunological Parameters of AIOJ/ BMD/FDOJ and BRONJ with Reversed Effects After BP Treatment}

Despite the similarities detailed in the section titled "Osteoimmunological parameters of AIOJ/BMD/FDOJ and BRONJ with the same impact in response to BPs", BRONJ and AIOJ/BMD/FDOJ present two very different clinical pictures; different reactions to $\mathrm{BP}$ administration are also likely to occur.

\section{RANKL Disorder as a Common Osteoimmunological Characteristic of BRONJ and AIOJ/BMD/FDOJ}

The initial involvement of RANKL in AIOJ/BMD/FDOJ has been described in the literature as follows: pathological increases in levels of R/C and MCP-3 from activated OBs stimulate chemotactic recruitment and RANKL formation of resorptive OCs and aggravate local osteolysis. However, BP administration indirectly inhibits OC maturation by increasing OPG protein secretion and decreases transmembrane RANKL expression in human OBs. Several studies have shown that although BPs do not significantly affect RANKL gene expression, they reduce transmembrane RANKL protein expression in OBs. ${ }^{68,69}$ This shows that BPs, in addition to directly inhibiting mature OCs, prevent $\mathrm{OC}$ recruitment and differentiation by splitting transmembrane RANKL into OBs. OC activation and RANKL activation in areas of AIOJ/ BMD/FDOJ, and OC inhibition and RANKL inhibition in BRONJ distinguish these two forms of derailed bone metabolism and thus yield different clinical results. Specifically, imperceptible fatty osteolysis of the marrow structures in AIOJ/BMD/FDOJ and painful BRONJ sequestrum arise as a result. BPs have been shown to downregulate the expression of RANKL, the OCdifferentiating factor produced by OBs. ${ }^{70}$

\section{Osteoprotegerin Disorder as a Common Osteoimmunological Characteristic of BRONJ and AIOJ/BMD/FDOJ}

The initial involvement of OPG in AIOJ/BMD/FDOJ is described in the literature. Since the TNF-a level found in $\mathrm{AIOJ} / \mathrm{BMD} / \mathrm{FDOJ}$ represents only $50 \%$ of the TNF-a level in healthy jawbone, ${ }^{36,37}$ the OPG enzyme that belongs to the TNF family is deactivated. In the resulting osteolysis found in areas of $\mathrm{AIOJ} / \mathrm{BMD} / \mathrm{FDOJ}$, this leads to reduced RANKL binding and thus results in $\mathrm{OC}$ activation. In conclusion, data from previously published studies have suggested that BPs modulate the production of OPG by normal OBs, which may contribute to the inhibition of OC bone resorption. ${ }^{71}$ As the production of OPG increases with OB maturation, the amplification of OPG by BPs may be linked to OB differentiation via stimulatory BP effects. BPs have been shown to increase the gene expression for the decoy receptor, OPG, in human OBs. ${ }^{71}$ OPG balance is disturbed in both AIOJ/BMD/FDOJ and BRONJ, albeit in opposite ways. However, the prior imbalance of OPG activity in AIOJ/BMD/FDOJ may increase the effects associated with BP administration.

\section{Common Diagnostic Parameters of AIOJ/ BMD/FDOJ and BRONJ}

With respect to the exposed variant of BRONJ, radiographic procedures are required in order to determine the extent to which the degree of ossification has increased. ${ }^{72}$ However, the existence of this variant of BRONJ is clinically evident. In contrast, the non-exposed BRONJ variant and $\mathrm{AIOJ} / \mathrm{BMD} / \mathrm{FDOJ}$ are associated with very similar problems in terms of diagnostic imaging. As with AIOJ/ $\mathrm{BMD} / \mathrm{FDOJ}$, the prevalence of this variant of BRONJ is largely underestimated as the disease is often underdiagnosed and under-reported. ${ }^{73}$ Studies have shown that almost a quarter of patients with BRONJ remain undiagnosed. ${ }^{74}$

\section{Histopathology as a Common Feature of BRONJ and AIOJ/BMD/FDOJ}

The initial histopathological presentation of $\mathrm{AIOJ} / \mathrm{BMD} /$ FDOJ found in the literature is as follows: Bouquot describes these bone modeling disorders as ischemic osteonecrosis, which is a bone disease characterized by the degeneration and death of marrow and bone due to a slow or abrupt decrease in marrow blood flow. ${ }^{75}$ Clumps of coalesced, liquefied fat (oil cysts) may be seen. Bone death is represented by a focal loss of OCs. Dark masses 
of calcific necrotic detritus may often be present. ${ }^{75}$ The histopathological features of AIOJ/BMD/FDOJ include necrotic adipocytes and fibrosis, but an almost complete absence of inflammatory cells. ${ }^{76}$ Additional research has shown the role of aseptic necrosis following injury or drug therapy in the pathophysiology of BRONJ. Aseptic bone necrosis, as found in AIOJ/BMD/FDOJ, has been reported as a manifestation of selected systemic diseases and also documented following operations, trauma, and immunosuppressive therapy at the site of BRONJ. ${ }^{77,78}$ The development of aseptic necrosis has been documented in the upper and lower jaw, particularly following osteotomies. ${ }^{79,80}$ Researchers have observed a relationship between oral BP use and non-specific aseptic osteonecrosis among a cohort of older cardiovascular patients. ${ }^{81}$ Other researchers have identified necrotic liquefaction, which often extend to large areas of the jaw, especially within BRONJ lesions of cancer patients, as shown using digital volume tomography (DVT)/cone beam computed tomography $(\mathrm{CBCT}){ }^{82}$ Research has been published on BRONJ samples that were characterized by low to moderate inflammation. ${ }^{83}$ This is in accordance with other reports of histopathological analyses of BRONJ samples. ${ }^{48,78,84-86}$ Bone samples from BRONJ patients were investigated by microscopy and the presence of inflammatory infiltrates in the bone tissues was not observed. ${ }^{87}$ These studies have demonstrated that aseptic necrosis, a lack of inflammatory reactions, and empty OC lacunae are common histopathological features of AIOJ/BMD/FDOJ and BRONJ.

\section{Imaging Difficulties as a Common Feature of BRONJ and AIOJ/BMD/FDOJ}

The diagnostic difficulties associated with BRONJ and $\mathrm{AIOJ} / \mathrm{BMD} / \mathrm{FDOJ}$ present another common feature. In order to diagnose BRONJ with imaging procedures, the Task Force Report of the American Society for Bone and Mineral Research highlights that the differential diagnosis of BRONJ should exclude other common intraoral diseases such as periodontitis, gingivitis, infectious osteomyelitis, osteoradionecrosis, neuralgia-inducing cavitational osteonecrosis ("NICO"), bone tumors, and metastases. ${ }^{15}$ The authors of the report thus rule out an etiological equation for diagnosing "NICO" and BRONJ. The current review is focused on the potential role of imaging techniques in the diagnosis of the early stages of BRONJ. A combination of clinical and radiological symptoms suggest that, while not specific to BRONJ, they may collectively be more comprehensive and representative of the bone disease process. ${ }^{2}$ The American Association of Maxillofacial Surgery accepts the use of imaging techniques when detecting BRONJ during presurgical evaluation. ${ }^{72}$ It is important for the BRONJ patient that various imaging methods be examined critically prior to being adopted for the early detection and diagnosis of BRONJ.

(a) Panoramic X-rays (2D-OPG): Panoramic X-rays (2D-OPG) are routinely used in clinical dentistry to assess jawbone status. Pathological changes may be completely absent in 2D-OPG without pathognomonic findings indicating the presence of BRONJ. ${ }^{88}$ The only radiological finding that is specific to BP therapy is that of "persistent alveolar socket"; even months following tooth removal or spontaneous tooth loss, the cortical walls of the alveolar bone remain intact without showing progressive destruction in response to osteolysis. ${ }^{89}$ 2D-OPG may adequately differentiate between osteonecrosis and metastases, but is less useful when the lesion is osteolytic..$^{90} 2 \mathrm{D}$ OPG is also helpful in cases where there is a mix of osteolysis and osteosclerosis; however, a significant loss of bone material $(30-50 \%)$ is required before image acquisition is optimal. ${ }^{91,92}$ This loss is unlikely to occur even in cases of NE-BRONJ before the lesion clinically manifests. 2D-OPG generates a $2 \mathrm{D}$ image showing significant overprojections that may hide important anatomical or pathological details. It is also difficult to delineate between the edges of necrotic and healthy bone, which often leads to overlooking early-stage lesions. ${ }^{90}$ Given these known limitations, we have excluded 2D-OPG in the assessment of NE-BRONJ and, for the same reasons, in the assessment of AIOJ/BMD/ FDOJ (see Figure 3). The medullary defects found in the latter present a similar diagnostic problem with respect to $2 \mathrm{D}-\mathrm{OPG}$ as those in cases of NE-BRONJ.

(b) Computed tomography (CT): As a method of 3D reconstruction, $\mathrm{CT}$ has the potential to detect both cancellous and cortical bone infections. ${ }^{93}$ CT can identify both osteosclerotic areas and areas of advanced BRONJ. However, CT scans are unable to provide additional information when compared to conventional X-ray 

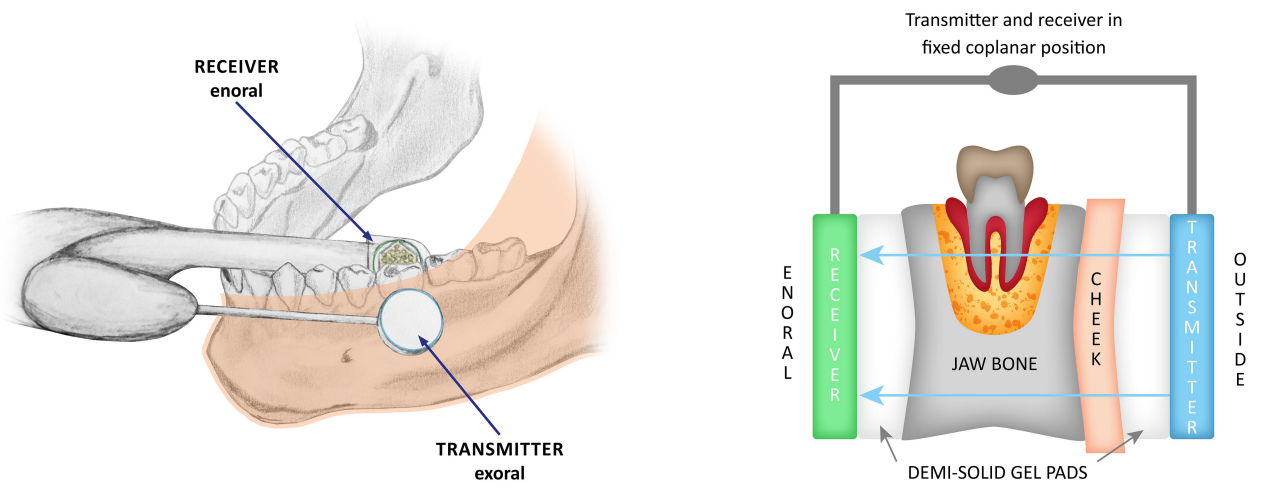

Figure 3 Left panel shows jawbone area 18; hematoxylin and eosin staining, magnification $\times 200$. The lower half of the image illustrates eosinophilic bone substance with empty osteocyte cavities corresponding to devitalized bone sequestrum. Middle part of the left panel: Highly irregular trabecular surfaces with a wide edging comprised of Actinomyces colonies surrounded by a wall of leukocytes. Upper part of left panel: Fibrin particles and individual lymphocytes. Right panel: Actinomyces granules visualized in a PAS reaction; the red color represents a broad band of granules in the middle. The lower edge of the right panel images once again shows a bone sequestrum and typically empty osteocyte lacunae. Diagnosis: Aseptic bone necrosis with Actinomyces colonization.

diagnostics in asymptomatic patients with osteonecrosis. $^{88}$ As the differences between cortical and trabecular bone may be identified with a CT scan, this imaging modality may be used in the differential diagnosis of BRONJ. ${ }^{92}$

(c) Cone beam computed tomography/digital volume tomography (CBCT/DVT): CBCT/DVT is a technique that employs lower radiation exposure $(<1 / 15$ of that required for CT), but has a higher spatial resolution when compared with conventional CT and provides a superior image quality, especially with respect to cancellous bone features. $^{94,95}$ Although the ability of CBCT/DVT to differentiate between the quality of soft tissue is limited due to low contrast resolution, this modality is able to provide detailed information about cortical thickness and integrity, medullary abnormalities following tooth extraction, and cancellous bone density. $^{82}$

\section{Magnetic Resonance Imaging (MRI) and Positron Emission Tomography (PET)}

The histopathological changes in necrotic bone may be visualized with MRI scans, as with CBCT/DVT. The images detect progressive cell death and the repair response (ie, edema). As the fat cells in normal bone marrow provide high signal intensity, it may be assumed that signal changes evident in the marrow are related to the death of fat cells. Necrotic adipocytes are a morphological characteristic of $\mathrm{AIOJ} / \mathrm{BMD} / \mathrm{FDOJ}{ }^{76}$ Following the application of a contrast agent, areas of ischemia may be identified as non-enhancing regions. Cases in which fibrosis and sclerosis of the bone occur may also result in lower signal intensity. Nevertheless, the currently available data on MRI results for BRONJ are limited, ${ }^{96}$ as are those related to AIOJ/BMD/FDOJ. Studies showed positronemission tomography (PET) as a sensitive method for diagnosis of BRONJ. Thus, PET could be useful for evaluating the severity of BRONJ. ${ }^{97}$

\section{Measurement of Bone Density with Transalveolar Ultrasound Sonography (TAU)}

2D-OPG is used to identify osteopathies of the jawbone. However, this imaging technique fails to show AIOJ/BMD/ FDJ areas, thus generating false-negative findings. As a result, $\mathrm{AIOJ} / \mathrm{BMD} / \mathrm{FDOJ}$ have been highly neglected in dentistry and medicine. ${ }^{98}$ Therefore, transalveolar ultrasound sonography (TAU) appears to be necessary as an additional imaging technique in order to improve the diagnosis of AIOJ/ BMD/FDOJ. ${ }^{99,100}$ A newly developed TAU device (TAU-n) measures sound velocity attenuation when the bone marrow has been penetrated. An ultrasound transmitter is placed over the jaw area and a thumbnail-sized receiver is placed inside the mouth. To obtain reproducible results when measuring bone density, the transmitter and receiver are arranged in a coplanar and fixed position. The parts of the receiving unit are placed inside a patient's mouth, the acoustic coupling between those parts and the alveolar ridge is performed with the aid of a semi-solid gel (Figure 3). With the receiver containing 91 piezoelectric fields, sound waves are registered and converted into a color graph of the corresponding areas 


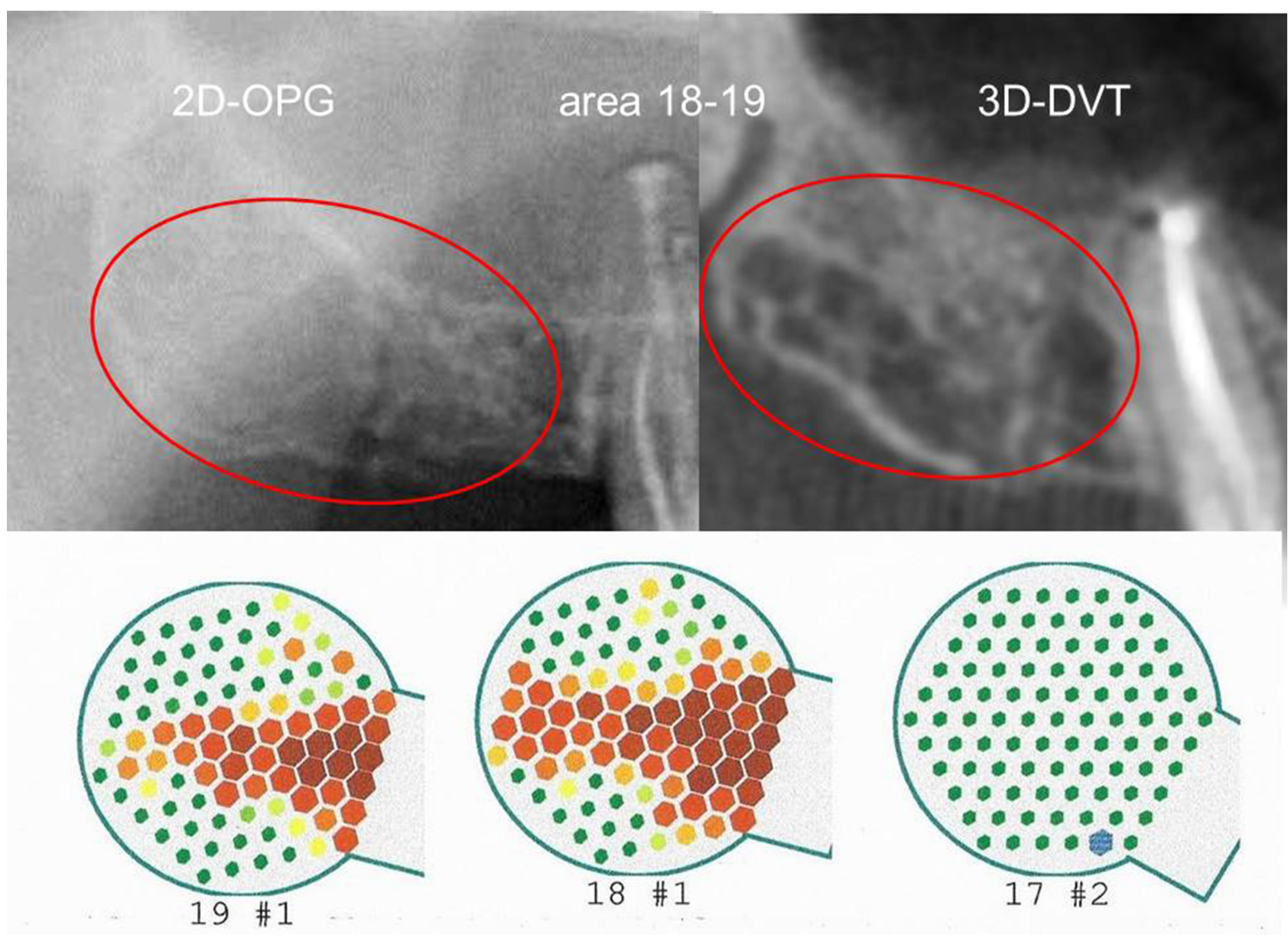

Figure 4 Left panel shows positioning of transmitter (outside) and receiver (enoral) in the lower jaw; the red band marks the cheek. Right panel shows the transmitter (in blue at the right) and receiver (in green at the left) in a fixed coplanar position (blue bar connecting the transmitter and receiver); semi-solid gel pads between the transmitter and the cheek on the outside of the mouth and between receiver and the alveolar ridge in the enoral position; trans-alveolar ultrasonic impulse from the transmitter to receiver (arrows in blue).

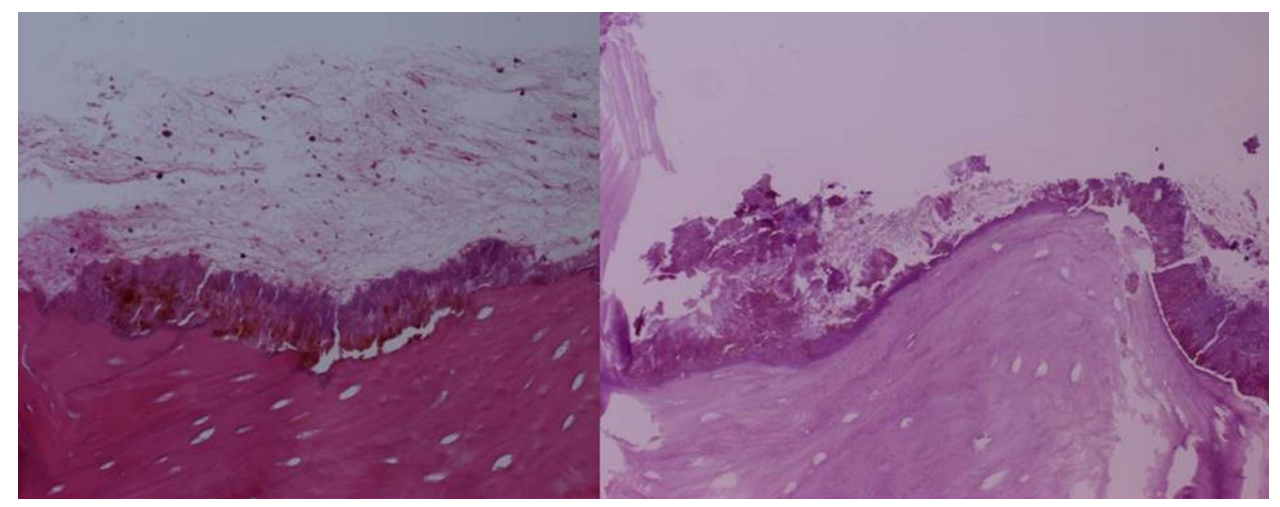

Figure 5 Inconspicuous 2D-OPG findings (left panel); suspected osteolytic processes in areas 17-19 in the sagittal section of the image using DVT (right panel). Lower panel: TAU measurement from region 17 to retromolar region 19. Legend: Green areas indicate normal bone density; yellow, orange, and red areas show decreasing bone density until complete osteolysis is reached. 
of bone density (Figure 4).On the graphic visualization, green indicates healthy, dense, and solid bone, yellow indicates the presence of ischemic metabolism, and orange and red highlight areas of $\mathrm{AIOJ} / \mathrm{BMD} / \mathrm{FDOJ}$ presence. ${ }^{101}$

\section{Case Descriptions of AIOJ/BMD/FDOJ, Non-Exposed BRONJ, and Actinomyces Colonization}

A clinical case of a 55-year-old patient with prostate carcinoma who was treated with parenteral BPs received an X-ray diagnosis of non-exposed BRONJ with normal intraoral findings in the right upper jawbone from area 17 to retromolar area 19. While 2D-OPG of area 18/19 showed no suspicious findings, the CBCT/DVT image demonstrated ossification irregularities and partial cavities that resembled AIOJ/BMD/FDOJ. The development and progression of BRONJ could not be reliably determined by reference to these images and it was not possible to make a differential diagnosis. In contrast, TAU-n images clearly indicated osteolysis (see Figure 4, below). The postoperative light microscopy findings from area 18/19 showed marrow with adipose tissue, significant fibrillar and myxoid degeneration of adipocytes, individual lymphocytes, and mast cells; however, no florid inflammation was observed. These are the typical histological features of AIOJ/BMD/FDOJ. ${ }^{76}$ It is worth noting, however, that there was a large bone sequestrum with empty OC cavities, highly irregular trabecular surfaces, and empty marrow spaces, with Actinomyces colonization (Figure 3).

Several reviews have indicated that light microscopy examinations were able to detect that $68.8 \%$ of BRONJ cases featured Actinomyces colonization. ${ }^{32}$ Anaerobic Actinomyces has long been associated with necrotic bone findings in BRONJ lesions. ${ }^{102}$ Actinomyces colonization is thus a top priority as a possible pathological trigger with respect to BRONJ. Since we have not identified bacterial colonization in areas of AIOJ/BMD/ FDOJ in our own studies, ${ }^{103}$ an accompanying secondary Actinomyces colonization seems to be an additional prerequisite for the development of BRONJ from an area of $\mathrm{AIOJ} / \mathrm{BMD} / \mathrm{FDOJ}$ in response to $\mathrm{BP}$ administration.

\section{Selection of Manuscripts for Review}

Table 1 displays all studies and their impact on the research question based on the inclusion and exclusion criteria in literature review.
Table I The Table Displays the Criteria for Inclusion of Specific Manuscripts in Our Research. Exclusion Criteria Were Unspecific Reviews Concentrating on Exposed BRONJ Only

\begin{tabular}{|l|l|}
\hline Criteria PubMed Research & $\begin{array}{l}\text { Number in } \\
\text { References }\end{array}$ \\
\hline $\begin{array}{l}\text { I. risk of BP therapy/BRONJ new } \\
\text { phenomenon }\end{array}$ & {$[1-19]$} \\
\hline 2. Staging BRONJ-Non-Exposed BRONJ & {$[20-26]$} \\
\hline 3. BP and antitumor therapy & {$[27-34]$} \\
\hline $\begin{array}{l}\text { 4. BP impact on AIOJ/BMD/FDOJ and } \\
\text { BRONJ }\end{array}$ & {$[35-71]$} \\
\hline $\begin{array}{l}\text { 5. Diagnosis of AIOJ/BMD/FDOJ and } \\
\text { BRONJ }\end{array}$ & {$[72-100]$} \\
\hline 5.I X-ray techniques/MRI/PET & {$[72-97]$} \\
\hline 5.2 Transalveolar ultrasonography (TAU) & {$[98-101]$} \\
\hline
\end{tabular}

\section{Discussion}

Can hitherto little-known, yet - according to our clinical experience $^{37,76}$ - epidemiologically widespread AIOJ/ $\mathrm{BMD} / \mathrm{FDOJ}$ represent cofactors in the development of BRONJ? The development of biological processes takes place in different stages and during various phases of transition. This also seems to be the case for BRONJ, as the exposed form found in the maxillofacial region represents the final, late-stage form of the NE-BRONJ variant. The focus of our study is thus on the early stage of BRONJ (Stage 0) without exposed bone, as based on the recommendations of the American Association of Oral and Maxillofacial Surgeons. 5,20,104 Our hypothesis considers the NE-BRONJ variant as one stage of development featuring an unrecognized BMD that is characteristic of $\mathrm{AIOJ} /$ $\mathrm{BMD} / \mathrm{FDOJ}$ and amplified by $\mathrm{BP}$ administration. The cumulative effects of BPs on pre-existing AIOJ/BMD/ FDOJ support this premise. The relationship between AIOJ/BMD/FDOJ and the administration of BPs (as shown in Figure 6) leads, etiologically, to the non-exposed BRONJ variant, which is less clearly described in the literature than the late-stage form of BRONJ, and also results in considerable oral impairment.

As BPs and AIOJ/BMD/FDOJ exert the same effects, resulting in the hyperfunctioning of $\mathrm{R} / \mathrm{C}$ expression, $\mathrm{OB}$ activity, hypoxia/ischemia, and the inhibition of OC activity, vascularization, and AP activity, AIOJ/BMD/FDOJ may be regarded as a prerequisite to the formation of BRONJ. 


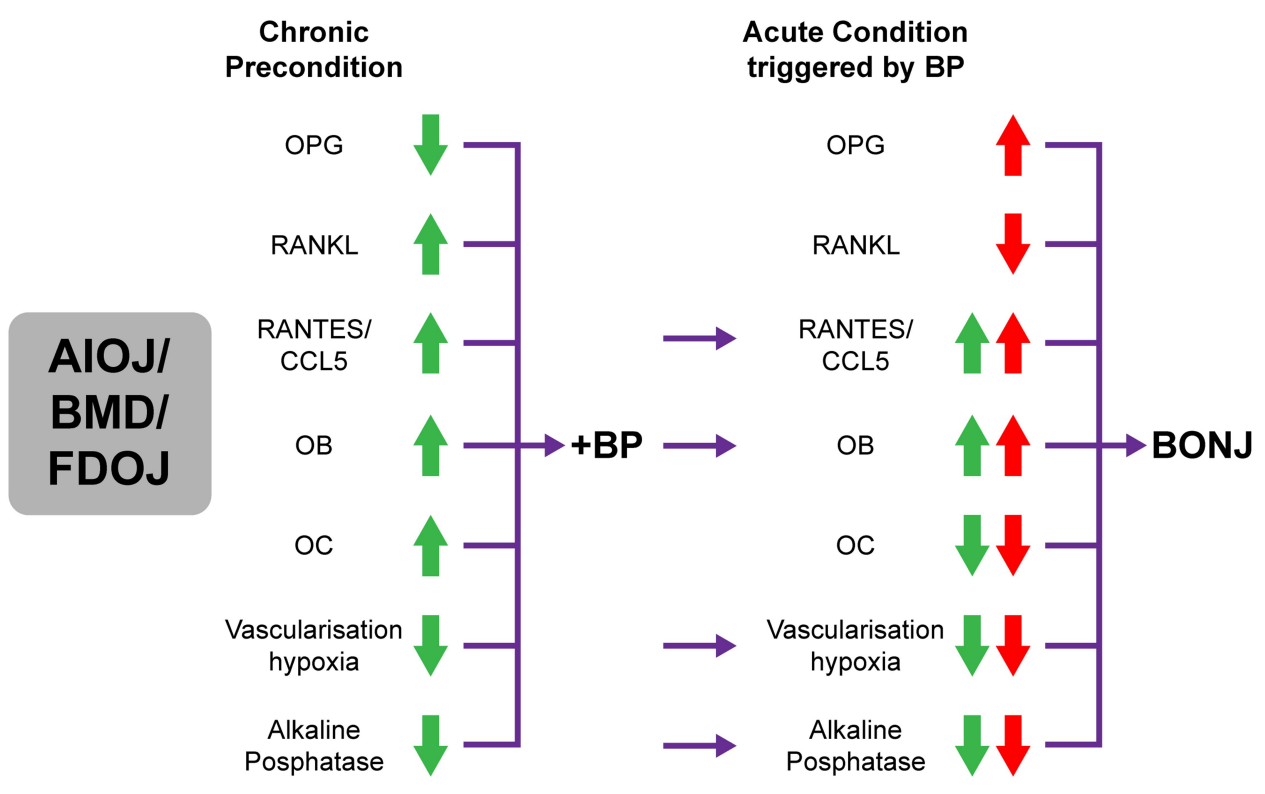

Figure 6 Overview of the individual osteoimmunological signal cascades present in AIOJ/BMD/FDOJ and their conversion or amplification following BP administration, resulting in the development of BRONJ. Legend: A pair of arrows, one red and one green, indicates the reinforcement or, in one instance, the reversal of the typical overexpression or inhibition found in AIOJ/BMD/FDOJ following BP administration.

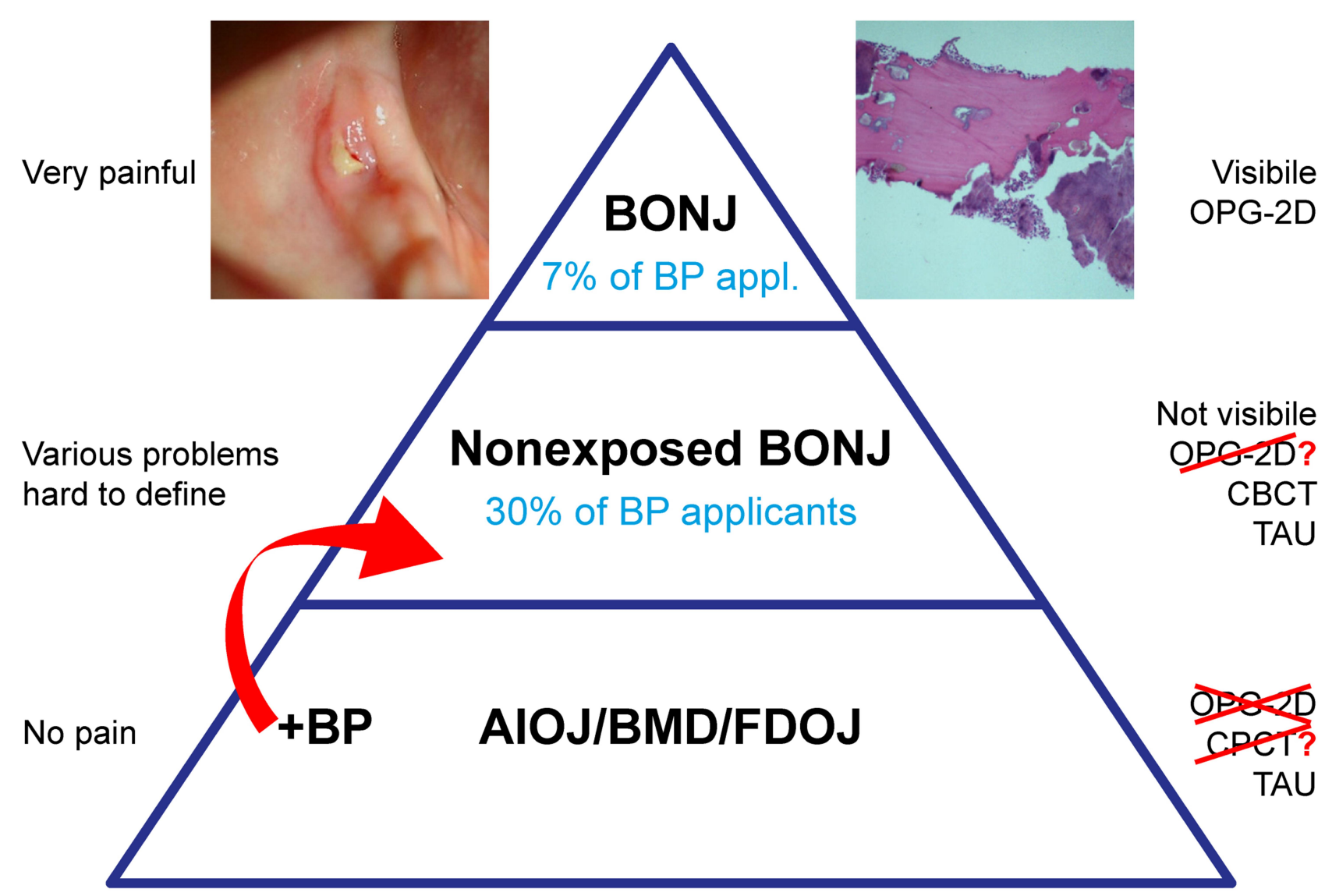

Figure 7 Three-step model for the development of BRONJ beginning with undetected AIOJ/BMD/FDOJ followed by the development of the NE-BRONJ variant, and finally by BRONJ.

Notes: Exposed bone BNOJ (left panel). Bony sequestrum BRONJ (right panel). Figure courtesy of Professor J Bouquot. 
Changes in silent $\mathrm{AIOJ} / \mathrm{BMD} / \mathrm{FDOJ}$ processes, including strongly inhibited OC production, reduced RANKL activity, and increased OPG activity, appear to induce the occurrence of BRONJ. Figure 7 presents a hypothetical three-step model detailing the basic stages for the development of BRONJ at $\mathrm{AIOJ} / \mathrm{BMD} / \mathrm{FDOJ}$ areas. Regions with fatty-degenerative changes may be the focal point for the subsequent development of BRONJ, as such changes may constitute an additional risk factor. This is consistent with the hypothesis described in the literature, whereby bone necrosis precedes clinically evident ONJ that is exposed through the oral mucosa. ${ }^{78,105}$ Regions featuring subclinical changes and necrotic bone may represent significant risk factors in the development of BRONJ. ${ }^{104}$ Further, it is known that patients at each stage exhibit a very different bone composition. ${ }^{104}$

\section{Conclusion}

The prevention of BRONJ is of paramount importance and has been repeatedly emphasized. ${ }^{106-108}$ Thus, BPs should not be regarded as the sole cause of osteonecrosis. The results of this study indicate that unresolved areas of wound healing at extraction sites - especially in former wisdom tooth areas may directly contribute to the pathogenesis of BRONJ. Other research has already described the involvement of the jaw in BRONJ as opposed to other bone sites. ${ }^{109}$ This may be because BPs are preferentially deposited in bones with high turnover rates such as the jawbone. The jawbone also presents with hidden conditions that - according to our hypothesis share common characteristics with those found in AIOJ/ $\mathrm{BMD} / \mathrm{FDOJ}$. Under the influence of BPs, areas of AIOJ/ $\mathrm{BMD} / \mathrm{FDOJ}$ may develop the pathological features of BRONJ. Efforts to prevent BRONJ, therefore, should not ignore the fact that BRONJ and $\mathrm{AIOJ} / \mathrm{BMD} / \mathrm{FDOJ}$ share similar osteoimmunological characteristics with respect to amplifying or reversing derailed signal cascades. Since $\mathrm{AIOJ} / \mathrm{BMD} / \mathrm{FDOJ}$ represent chronic, subclinical states, the sudden formation of BRONJ may be interpreted as a subsequent acute event. The early detection of BRONJ (as well as $\mathrm{AIOJ} / \mathrm{BMD} / \mathrm{FDOJ}$ ) using X-ray techniques appears to be difficult. A new risk-benefit analysis should be considered: Patients should be screened for hidden oral risk factors, such as AIOJ/BMD/FDOJ. Thus, TAU may be used to measure bone density and fill this diagnostic gap. When parenteral BP therapy is administered, periodontal prophylaxis and tooth restoration should take precedence; ${ }^{110,111}$ furthermore, AIOJ/ $\mathrm{BMD} / \mathrm{FDOJ}$ should be diagnosed first, preferably (and accurately) with TAU-n, and then surgically eliminated. The formation of difficult-to-treat BRONJ could be avoided in certain cases if the exacerbation of pre-existing areas of $\mathrm{AIOJ} / \mathrm{BMD} / \mathrm{FDOJ}$ is prevented before initiating antitumorigenic BP therapy. Surgical opening of the cortex, removal of ischemic marrow, and accompanying wound care represent the only way to address cases of AIOJ/BMD/ FDOJ. ${ }^{112}$ Consultation with an oncologist is mandatory, as the oncologist may insist on radiation therapy and the prevention of osteoradionecrosis of the jawbones via tooth restoration. To the best of our knowledge, we have highlighted, for the first time, the possible impact chains flowing from AIOJ/BMD/FDOJ and leading to the development of NE-BRONJ and further to exposed BRONJ. We also support the hypothesis presented herein with scientific data from the available literature. Due to the lack of clinical studies investigating these impact chains, multiple studies are necessary to elucidate the hypothesized relationships.

\section{Abbreviations}

AIOJ, aseptic-ischemic osteonecrosis of the jawbone; BMD, bone marrow defects; BRONJ, bisphosphonate (BP)-related osteonecrosis of the jaw; CBCT, cone beam computed tomography; CCL5, chemokine (C-C motif) ligand 5; DVT, digital volume tomography; FDOJ, fatty-degenerative osteonecrosis/osteolysis of the jawbone; HU, hounsfield units; OPG, orthopantomogram; R/C, RANTES/CCL5; RANTES, regulated on activation, normal $\mathrm{T}$ cell expressed and secreted; TAU, transalveolar ultrasonography; TAU-n, new transalveolar ultrasonography device.

\section{Ethics and Consent Statement}

Hereby we confirm that written informed consent has been provided by the patient to have the case details and any accompanying images published. The data were collected as part of the normal everyday medical care of the patients and evaluated retrospectively. Institutional approval was not required to publish the case details.

\section{Acknowledgments}

English language editing of this manuscript was provided by Journal Prep Services. Additional English language editing was provided by Natasha Gabriel.

\section{Funding}

This research did not receive any specific grant from funding agencies in the public, commercial, or not-forprofit sectors. 


\section{Disclosure}

The corresponding author, Johann Lechner, is the holder of a patent used in the TAU-n apparatus and its associated software and reports a patent CaviTAU licensed to Dr. Johann Lechner. Bernd Zimmermann is an employee of QINNO. The authors report no other potential conflicts of interest for this work.

\section{References}

1. Ruggiero SL, Dodson TB, Fantasia J, et al. American Association of Oral and Maxillofacial Surgeons position paper on medication-related osteonecrosis of the jaw-2014 update. J Oral Maxillofacial Surg. 2014;72:1938-1956. doi:10.1016/j.joms.2014.04.031.

2. Khan A, Sandor G, Dore E, et al. Canadian consensus practice guidelines for bisphosphonate associated osteonecrosis of the jaw. J Rheumatol. 2008;35:1391-1397.

3. Marx RE. Pamidronate (Aredia) and zoledronate (Zometa) induced avascular necrosis of the jaws: a growing epidemic. $J$ Oral Maxillofacial Surg. 2003;61:1115-1117. doi:10.1016/S02782391(03)00720-1.

4. Rosenberg T, Ruggiero S. Osteonecrosis of the jaws associated with the use of bisphosphonates. J Oral Maxillofac Surg. 2003;61:60. doi:10.1016/S0278-2391(03)00566-4

5. Wang J, Goodger NM, Pogrel MA. Osteonecrosis of the jaws associated with cancer chemotherapy. J Oral Maxillofacial Surg. 2003;61:1104-1107. doi:10.1016/S0278-2391(03)00328-8.

6. van Dessel J, Ferreira Pinheiro Nicolielo L, Huang Y, et al. Quantification of bone quality using different cone-beam CT devices: accuracy assessment for edentulous human mandibles. Eur J Oral Implantol. 2016;9:411-424.

7. Imada T, van Dessel J, Rubira-Bullen I, Santos P. Long-term effects of zoledronic acid on alveolar bone remodeling and quality in the jaw of an oncological rat model. Dent Craniofacial Res. 2018;1.

8. Marx RE, Sawatari Y, Fortin M, Broumand V. Bisphosphonateinduced exposed bone (osteonecrosis/osteopetrosis) of the jaws: risk factors, recognition, prevention, and treatment. J Oral Maxillofacial Surg. 2005;63:1567-1575. doi:10.1016/j.joms.2005.07.010.

9. Palomo L, Bissada N, Liu J. Bisphosphonate therapy for bone loss in patients with osteoporosis and periodontal disease: clinical perspectives and review of the literature. Quintessence Int. 2006;37:103-107.

10. Vahtsevanos K, Kyrgidis A, Verrou E, et al. Longitudinal cohort study of risk factors in cancer patients of bisphosphonate-related osteonecrosis of the jaw. J Clin Oncol. 2009;27:5356-5362. doi:10.1200/JCO.2009.21.9584.

11. Kyrgidis A, Vahtsevanos K, Koloutsos G, et al. Bisphosphonaterelated osteonecrosis of the jaws: a case-control study of risk factors in breast cancer patients. $J$ Clin Oncol. 2008;26:4634-4638. doi:10.1200/JCO.2008.16.2768.

12. Palaska PK, Cartsos V, Zavras AI. Bisphosphonates and time to osteonecrosis development. Oncologist. 2009;14:1154-1166. doi:10.1634/theoncologist.2009-0115.

13. Stopeck AT, Lipton A, Body JJ, et al. Denosumab compared with zoledronic acid for the treatment of bone metastases in patients with advanced breast cancer: a randomized, double-blind study. J Clin Oncol. 2010;28:5132-5139. doi:10.1200/JCO.2010.29.7101.

14. Lipton A, Fizazi K, Stopeck AT, et al. Superiority of denosumab to zoledronic acid for prevention of skeletal-related events: a combined analysis of 3 pivotal, randomised, Phase 3 trials. Eur $J \quad$ Cancer. 2012;48:3082-3092. doi:10.1016/j. ejca.2012.08.002.
15. Khosla S, Burr D, Cauley J, et al. Bisphosphonate-associated osteonecrosis of the jaw: report of a task force of the American Society for Bone and Mineral Research. $J$ Bone Min Res. 2007;22:1479-1491. doi:10.1359/jbmr.0707onj.

16. Kühl S, Walter C, Acham S, Pfeffer R, Lambrecht JT. Bisphosphonate-related osteonecrosis of the jaws - a review. Oral Oncol. 2012;48:938-947. doi:10.1016/j.oraloncology.2012.03.028.

17. Bamias A, Kastritis E, Bamia C, et al. Osteonecrosis of the jaw in cancer after treatment with bisphosphonates: incidence and risk factors. $J$ Clin Oncol. 2005;23:8580-8587. doi:10.1200/ JCO.2005.02.8670.

18. Mavrokokki T, Cheng A, Stein B, Goss A. Nature and frequency of bisphosphonate-associated osteonecrosis of the jaws in Australia. J Oral Maxillofacial Surg. 2007;65:415-423. doi:10.1016/j.joms.2006.10.061.

19. Gutta R, Louis PJ. Bisphosphonates and osteonecrosis of the jaws: science and rationale. Oral Surg Oral Med Oral Pathol Oral Radiol Endodontol. 2007;104:186-193. doi:10.1016/j. tripleo.2006.12.004.

20. Ruggiero SL, Dodson TB, Assael LA, Landesberg R, Marx RE, Mehrotra B. American Association of Oral and Maxillofacial Surgeons position paper on bisphosphonate-related osteonecrosis of the jaws-2009 update. J Oral Maxillofacial Surg. 2009;67:2-12. doi:10.1016/j.joms.2009.01.009.

21. Patel S, Choyee S, Uyanne J, et al. Non-exposed bisphosphonate-related osteonecrosis of the jaw: a critical assessment of current definition, staging, and treatment guidelines. Oral Dis. 2012;18:625-632. doi:10.1111/j.1601-0825.2012.01911.x.

22. Yarom N, Fedele S, Lazarovici TS, Elad S. Is exposure of the jawbone mandatory for establishing the diagnosis of bisphosphonate-related osteonecrosis of the jaw? J Oral Maxillofacial Surg. 2010;68:705. doi:10.1016/j.joms.2009.07.086.

23. Mignogna MD, Sadile G, Leuci S. Drug-related osteonecrosis of the jaws: "Exposure, or not exposure: that is the question". Oral Surg Oral Med Oral Pathol Oral Radiol. 2012;113:704-705. doi:10.1016/j.0ooo.2012.01.004.

24. Junquera L, Gallego L. Nonexposed bisphosphonate-related osteonecrosis of the jaws: another clinical variant? $J$ Oral Maxillofacial Surg. 2008;66:1516-1517. doi:10.1016/j. joms.2008.02.012.

25. Fedele S, Porter SR, D'Aiuto F, et al. Nonexposed variant of bisphosphonate-associated osteonecrosis of the jaw: a case series. Am J Med. 2010;123:1060-1064. doi:10.1016/j. amjmed.2010.04.033.

26. Schiodt M, Reibel J, Oturai P, Kofod T. Comparison of nonexposed and exposed bisphosphonate-induced osteonecrosis of the jaws: a retrospective analysis from the Copenhagen cohort and a proposal for an updated classification system. Oral Surg Oral Med Oral Pathol Oral Radiol. 2014;117:204-213. doi:10.1016/j. oooo.2013.10.010.

27. Gnant M, Mlineritsch B, Stoeger H, et al. Adjuvant endocrine therapy plus zoledronic acid in premenopausal women with early-stage breast cancer: 62-month follow-up from the ABCSG-12 randomised trial. Lancet Oncol. 2011;12:631-641. doi:10.1016/S1470-2045(11)70122-X.

28. Deans RJ, Moseley AB. Mesenchymal stem cells. Exp Hematol. 2000;28:875-884. doi:10.1016/S0301-472X(00)00482-3.

29. Karnoub AE, Dash AB, Vo AP, et al. Mesenchymal stem cells within tumour stroma promote breast cancer metastasis. Nature. 2007;449:557-563. doi:10.1038/nature06188.

30. Psaila B, Lyden D. The metastatic niche: adapting the foreign soil. Nat Rev Cancer. 2009;9:285-293. doi:10.1038/nrc2621.

31. Gallo M, de Luca A, Lamura L, Normanno N. Zoledronic acid blocks the interaction between mesenchymal stem cells and breast cancer cells: implications for adjuvant therapy of breast cancer. Ann Oncol. 2012;23:597-604. doi:10.1093/annonc/mdr159. 
32. Hinson AM, Smith CW, Siegel ER, Stack BC. Is bisphosphonate-related osteonecrosis of the jaw an infection? A histological and microbiological ten-year summary. Int J Dent. 2014;2014:1-7. doi:10.1155/2014/452737.

33. Wood J, Bonjean K, Ruetz S, et al. Novel antiangiogenic effects of the bisphosphonate compound zoledronic acid. J Pharmacol Exp Ther. 2002;302:1055-1061. doi:10.1124/jpet.102.035295.

34. Glueck CJ, McMahon RE, Bouquot JE, Triplett D. Exogenous estrogen may exacerbate thrombophilia, impair bone healing and contribute to development of chronic facial pain. $C R A N I O^{\circledR}$. 1998;16:143-153. doi:10.1080/08869634.1998.11746052.

35. Gonzalez RM, Daly DS, Tan R, Marks JR, Zangar RC. Plasma biomarker profiles differ depending on breast cancer subtype but RANTES is consistently increased. Cancer Epidemiol Biomarkers Prev. 2011;20:1543-1551. doi:10.1158/1055-9965. EPI-10-1248.

36. Lechner J, von Baehr V. Hyperactivated signaling pathways of chemokine RANTES/CCL5 in osteopathies of jawbone in breast cancer patients-case report and research. Breast Cancer. 2014;8:89-96. doi:10.4137/BCBCR.S15119.

37. Lechner J, von Baehr V. Chemokine RANTES/CCL5 as an unknown link between wound healing in the jawbone and systemic disease: is prediction and tailored treatments in the horizon? EPMA J. 2015;6:10. doi:10.1186/s13167-015-0032-4.

38. Lechner J, von Baehr V. RANTES and fibroblast growth factor 2 in jawbone cavitations: triggers for systemic disease? Int $J$ Gen Med. 2013;6:277-290. doi:10.2147/IJGM.S43852.

39. Lechner J, von B. RANTES and fibroblast growth factor 2 in jawbone cavitations: triggers for systemic disease? Int J Gen Med. 2013;277. doi:10.2147/IJGM.S43852.

40. Greiner S, Kadow-Romacker A, Lübberstedt M, Schmidmaier G, Wildemann B. The effect of zoledronic acid incorporated in a poly(D,L-lactide) implant coating on osteoblasts in vitro. J Biomed Mater Res A. 2007;80A:769-775. doi:10.1002/jbm. a.30950.

41. Troeltzsch $M$, Kriegelstein S, Messlinger $\mathrm{K}$, Steiner $\mathrm{T}$, Messlinger K, Troeltzsch M. Physiology and pharmacology of nonbisphosphonate drugs implicated in osteonecrosis of the jaw. $J$ Can Dent Assoc. 2012;78:c85.

42. Krüger TB, Herlofson BB, Landin MA, Reseland JE. Alendronate alters osteoblast activities. Acta Odontol Scand. 2016;74:550-557. doi:10.1080/00016357.2016.1217041.

43. Bouquot $\mathrm{J}$, McMahon $\mathrm{R}$ The histopathology of chronic ischemic bone disease $(\mathrm{ON})$ - parameters and disease classification. Tucson, Arizona: Proceedings of the Annual Meeting of the American Association of Oral \& Maxillofacial Pathology; 2010.

44. Assael LA. New foundations in understanding osteonecrosis of the jaws. $J$ Oral Maxillofacial Surg. 2004;62:125-126. doi:10.1016/j.joms.2003.11.009.

45. Kenzora J, Glimcher M. Accumulative cell stress: the multifactorial etiology of idiopathic osteonecrosis. Orthop Clin North Am. 1985; 16:669-679.

46. Schoutens A, Arlet J, Gardeniers J, Hughes S, editors. Bone Circulation and Vascularization in Normal and Pathological Conditions. New York, NY: Plenum Press; 1993.

47. Arlet J, Mazieres B. Bone Circulation and Bone Necrosis. Heidelberg, Germany: Springer-Verlag; 1990.

48. Favia G, Pilolli GP, Maiorano E. Histologic and histomorphometric features of bisphosphonate-related osteonecrosis of the jaws: an analysis of 31 cases with confocal laser scanning microscopy. Bone. 2009;45:406-413. doi:10.1016/j. bone.2009.05.008.

49. Paparella ML, Brandizzi D, Santini-Araujo E, Cabrini RL. Histopathological features of osteonecrosis of the jaw associated with bisphosphonates. Histopathology. 2012;60:514-516. doi:10.1111/j.1365-2559.2011.04061.x.
50. Gruppo R, Glueck CJ, Mcmahon RE, et al. The pathophysiology of alveolar osteonecrosis of the jaw: anticardiolipin antibodies, thrombophilia, and hypofibrinolysis. $J$ Lab Clin Med. 1996;127:481-488. doi:10.1016/S0022-2143(96)90065-7.

51. Glueck CJ, McMahon RE, Bouquot J, et al. Thrombophilia, hypofibrinolysis, and alveolar osteonecrosis of the jaws. Oral Surg Oral Med Oral Pathol Oral Radiol Endodontol. 1996;81:557-566. doi:10.1016/S1079-2104(96)80047-3.

52. Glueck C, Freiberg R, Gruppo R. Osteonecrosis: Etiology, Diagnosis, and Treatment. Rosemont, IL: American Academy of Orthopaedic Surgeons; 1997.

53. Gabriel H, Fitzgerald SW, Myers MT, Donaldson JS, Poznanski AK. MR imaging of hip disorders. RadioGraphics. 1994;14:763-781. doi:10.1148/radiographics.14.4.7938767.

54. Votta BJ, White JR, Dodds RA, et al. CKbeta-8 [CCL23], a novel $\mathrm{CC}$ chemokine, is chemotactic for human osteoclast precursors and is expressed in bone tissues. $J$ Cell Physiol. 2000;183:196-207. doi:10.1002/(SICI)1097-4652(200005) 183:2<96::aid-jcp6>3.0.CO;2-8.

55. Lisignoli G, Toneguzzi S, Grassi F, et al. Different chemokines are expressed in human arthritic bone biopsies: IFN- $\gamma$ and IL-6 differently modulate IL-8, MCP-1 AND RANTES production by arthritic osteoblasts. Cytokine. 2002;20:231-238. doi:10.1006/ cyto.2002.2006.

56. Pozzi S, Vallet S, Mukherjee S, et al. High-dose zoledronic acid impacts bone remodeling with effects on osteoblastic lineage and bone mechanical properties. Clin Cancer Res. 2009;15:5829-5839. doi:10.1158/1078-0432.CCR-09-0426.

57. Kamalakar A, Bendre MS, Washam CL, et al. Circulating interleukin-8 levels explain breast cancer osteolysis in mice and humans. Bone. 2014;61:176-185. doi:10.1016/j. bone.2014.01.015.

58. Yao Z, Li P, Zhang Q, et al. Tumor necrosis factor- $\alpha$ increases circulating osteoclast precursor numbers by promoting their proliferation and differentiation in the bone marrow through upregulation of c-Fms expression. $J$ Biol Chem. 2006;281:11846-11855. doi:10.1074/jbc.M512624200.

59. Roodman GD. Cell biology of the osteoclast. Exp Hematol. 1999;27:1229-1241. doi:10.1016/S0301-472X(99)00061-2.

60. Kim N, Kadono Y, Takami M, et al. Osteoclast differentiation independent of the TRANCE-RANK-TRAF6 axis. J Exp Med. 2005;202:589-595. doi:10.1084/jem.20050978.

61. Zhang Q, Badell IR, Schwarz EM, et al. Tumor necrosis factor prevents alendronate-induced osteoclast apoptosis in vivo by stimulating Bcl-xL expression through Ets-2. Arthritis Rheum. 2005;52:2708-2718. doi:10.1002/art.21236.

62. Lechner J, Rudi T, von Baehr V. Osteoimmunology of tumor necrosis factor-alpha, IL-6, and RANTES/CCL5: a review of known and poorly understood inflammatory patterns in osteonecrosis. Clin Cosmet Investig Dent. 2018;10:251-262. doi:10.2147/CCIDE.S184498.

63. Oral complications of chemotherapy and head/neck radiation $\left(\mathrm{PDQ}^{\circledR}\right)$; 2006. Available from: http://www.cancer.gov/cancerto pics/pdq/supportivecare/oral-complications/HealthProfessional. Accessed December 30, 2020

64. Sims NA, Green JR, Glatt M, et al. Targeting osteoclasts with zoledronic acid prevents bone destruction in collagen-induced arthritis. Arthritis Rheum. 2004;50:2338-2346. doi:10.1002/ art.20382.

65. Jensen ED, Gopalakrishnan R, Westendorf JJ. Regulation of gene expression in osteoblasts. BioFactors. 2010;36:25-32. doi:10.1002/biof.72.

66. Vaisman DN, McCarthy AD, Cortizo AM. Bone-specific alkaline phosphatase activity is inhibited by bisphosphonates: role of divalent cations. Biol Trace Elem Res. 2005;104:131-140. doi:10.1385/BTER:104:2:131. 
67. Klein B, Ben-Bassat H, Breuer E, Solomon V, Golomb G. Structurally different bisphosphonates exert opposing effects on alkaline phosphatase and mineralization in marrow osteoprogenitors. Cell Biochem. 1998;68:186-194. doi:10.1002/ (SICI) 1097-4644(19980201)68:2<186::AID-JCB5>3.0.CO;2-R

68. Pan B, Farrugia AN, To LB, et al. The nitrogen-containing bisphosphonate, zoledronic acid, influences RANKL expression in human osteoblast-like cells by activating TNF- $\alpha$ converting enzyme (TACE). $J$ Bone Min Res. 2004;19:147-154. doi:10.1359/jbmr.2004.19.1.147.

69. Taylor KH, Middlefell LS, Mizen KD. Osteonecrosis of the jaws induced by anti-RANK ligand therapy. Br J Oral Maxillofacial Surg. 2010;48:221-223. doi:10.1016/j.bjoms.2009.08.030.

70. Mackie PS, Fisher JL, Zhou H, Choong PFM. Bisphosphonates regulate cell growth and gene expression in the UMR 106-01 clonal rat osteosarcoma cell line. $\mathrm{Br} J$ Cancer. 2001;84:951-958. doi:10.1054/bjoc.2000.1679.

71. Viereck V, Emons G, Lauck V, et al. Bisphosphonates pamidronate and zoledronic acid stimulate osteoprotegerin production by primary human osteoblasts. Biochem Biophys Res Commun. 2002;291:680-686. doi:10.1006/bbrc.2002.6510.

72. American Association of Maxillofacial Surgery. Parameters of care. Clinical practice guidelines for oral and maxillofacial surgery (AAOMS ParCare 2012). J Oral Maxil Surg. 2012;70.

73. Fusco V, Galassi C, Berruti A, et al. Osteonecrosis of the jaw after zoledronic acid and denosumab treatment. J Clin Oncol. 2011;29: e521-2. doi:10.1200/JCO.2011.35.1551.

74. Fedele S, Bedogni G, Scoletta M, et al. Up to a quarter of patients with osteonecrosis of the jaw associated with antiresorptive agents remain undiagnosed. Br J Oral Maxillofacial Surg. 2015;53:13-17. doi:10.1016/j.bjoms.2014.09.001.

75. Neville B, Damm D, Allen C, Bouquot J. Oral and Maxillofacial Pathology. 4th ed. Elsevier Health Sciences; 2008.

76. Lechner J, von Baehr V. Peripheral neuropathic facial/trigeminal pain and RANTES/CCL5 in jawbone cavitation. Evid Based Complement Alt Med. 2015;2015:1-9. doi:10.1155/2015/582520.

77. McCarthy E. Aseptic necrosis of bone: an historic perspective. Clin Orthop. 1982;216-221.

78. Lesclous P, Abi Najm S, Carrel J-P, et al. Bisphosphonateassociated osteonecrosis of the jaw: a key role of inflammation? Bone. 2009;45:843-852. doi:10.1016/j.bone.2009.07.011.

79. Lanigan DT, West RA. Aseptic necrosis of the mandible: report of two cases. J Oral Maxillofacial Surg. 1990;48:296-300. doi:10.1016/0278-2391(90)90397-K.

80. Lanigan DT, Hey JH, West RA. Aseptic necrosis following maxillary osteotomies: report of 36 cases. J Oral Maxillofacial Surg. 1990;48:142-156. doi:10.1016/S02782391(10)80202-2.

81. Etminan M, Aminzadeh K, Matthew IR, Brophy JM. Use of oral bisphosphonates and the risk of aseptic osteonecrosis: a nested case-control study. $J$ Rheumatol. 2008;35:691-695.

82. Barragan-Adjemian C, Lausten L, Ang DB, Johnson M, Katz J, Bonewald LF. Bisphosphonate-related osteonecrosis of the jaw: model and diagnosis with cone beam computerized tomography. Cells Tissues Organs. 2009;189:284-288. doi:10.1159/ 000151451.

83. Cardemil C, Thomsen P, Larsson Wexell C. Jaw bone samples from bisphosphonate-treated patients: a pilot cohort study. Clin Implant Dent Relat Res. 2015;17:e679-91. doi:10.1111/ cid.12307.

84. Hansen T, Kirkpatrick CJ, Walter C, Kunkel M. Increased numbers of osteoclasts expressing cysteine proteinase cathepsin $\mathrm{K}$ in patients with infected osteoradionecrosis and bisphosphonate-associated osteonecrosis-a paradoxical observation? Virchows Archiv. 2006;449:448-454. doi:10.1007/s00428-0060261-y.
85. Hoefert S, Schmitz I, Tannapfel A, Eufinger H. Importance of microcracks in etiology of bisphosphonate-related osteonecrosis of the jaw: a possible pathogenetic model of symptomatic and non-symptomatic osteonecrosis of the jaw based on scanning electron microscopy findings. Clin Oral Investig. 2010;14 (3):271-284. doi:10.1007/s00784-009-0300-6.

86. Carmagnola D, Canciani E, Sozzi D, Biglioli F, Moneghini L, Dellavia C. Histological findings on jaw osteonecrosis associated with bisphosphonates (BRONJ) or with radiotherapy (ORN) in humans. Acta Odontol Scand. 2013;71:1410-1417. doi:10.3109/ 00016357.2013.765592.

87. Perrotta I, Cristofaro MG, Amantea M, et al. Jaw osteonecrosis in patients treated with bisphosphonates: an ultrastructural study. Ultrastruct Pathol. 2010;34:207-213. doi:10.3109/ 01913121003729806.

88. Stockmann P, Hinkmann FM, Lell MM, et al. Panoramic radiograph, computed tomography or magnetic resonance imaging. Which imaging technique should be preferred in bisphosphonate-associated osteonecrosis of the jaw? A prospective clinical study. Clin Oral Investig. 2010;14:311-317. doi:10.1007/s00784-009-0293-1.

89. Groetz KA, Al-Nawas B. Persisting alveolar sockets-a radiologic symptom of BP-ONJ? J Oral Maxillofacial Surg. 2006;64:1571-1572. doi:10.1016/j.joms.2006.05.041.

90. Store G, Larheim T. Mandibular osteoradionecrosis: a comparison of computed tomography with panoramic radiography. Dentomaxillofac Radiol. 1999;28:295-300. doi:10.1038/sj. dmfr.4600461

91. Store G, Boysen M. Mandibular osteoradionecrosis: clinical behaviour and diagnostic aspects. Clin Otolaryngol Allied Sci. 2000;25:378-384. doi:10.1046/j.1365-2273.2000.00367.x.

92. Chiandussi S, Biasotto M, Dore F, Cavalli F, Cova M, Di Lenarda R. Clinical and diagnostic imaging of bisphosphonate-associated osteonecrosis of the jaws. Dentomaxillofacial Radiol. 2006;35:236-243. doi: $10.1259 / \mathrm{dmfr} / 27458726$.

93. Taguchi A, Akiyama H, Koseki T, Shimizutani K. Recognition of bisphosphonate-related osteonecrosis of the jaw among oral and maxillofacial radiologists: results from a questionnaire-based survey in Japan. Oral Radiol. 2013;29:98-104. doi:10.1007/s11282012-0114-0.

94. Schulze D, Blessmann M, Pohlenz P, Wagner K, Heiland M. Diagnostic criteria for the detection of mandibular osteomyelitis using cone-beam computed tomography. Dentomaxillofacial Radiol. 2006;35:232-235. doi:10.1259/dmfr/71331738.

95. Guerrero ME, Jacobs R, Loubele M, Schutyser F, Suetens P, van Steenberghe D. State-of-the-art on cone beam CT imaging for preoperative planning of implant placement. Clin Oral Investig. 2006;10:1-7. doi:10.1007/s00784-005-0031-2.

96. Bisdas S, Chambron Pinho N, Smolarz A, Sader R, Vogl TJ, Mack MG. Biphosphonate-induced osteonecrosis of the jaws: CT and MRI spectrum of findings in 32 patients. Clin Radiol. 2008;63:71-77. doi:10.1016/j.crad.2007.04.023.

97. Wilde F, Steinhoff K, Frerich B, et al. Positron-emission tomography imaging in the diagnosis of bisphosphonate-related osteonecrosis of the jaw. Oral Surg Oral Med Oral Pathol Oral Radiol Endodontol. 2009;3:107. doi:10.1016/j.tripleo.2008.09.019

98. Kumar VV, Sagheb K, Klein MO, Al-Nawas B, Kann PH, Kämmerer PW. Relation between bone quality values from ultrasound transmission velocity and implant stability parameters - an ex vivo study. Clin Oral Implants Res. 2012;23:975-980. doi:10.1111/j.1600-0501.2011.02250.x.

99. Al-Nawas B, Grötz KA, Rose E, Duschner H, Kann P, Wagner W. Using ultrasound transmission velocity to analyse the mechanical properties of teeth after in vitro, in situ, and in vivo irradiation. Clin Oral Investig. 2000;4:168-172. doi:10.1007/ s007840000068. 
100. Bouquot J, Shankland WI, Margolis M. Through-transmission alveolar ultrasonography (TAU) - new technology for evaluation of bone density and desiccation. Comparison with radiology of 170 biopsied alveolar sites of osteoporotic and ischemic damage. Oral Surg Oral Med Oral Pathol Oral Radiol Endod. 2002;93:413-414.

101. Lechner J, Zimmermann B, Schmidt M, von Baehr V. Ultrasound sonography to detect focal osteoporotic jawbone marrow defects: clinical comparative study with corresponding hounsfield units and RANTES/CCL5 expression. Clin Cosmet Investig Dent. 2020;12:205-216. doi:10.2147/CCIDE.S247345.

102. Tsurushima H, Kokuryo S, Sakaguchi O, Tanaka J, Tominaga K. Bacterial promotion of bisphosphonate-induced osteonecrosis in Wistar rats. Int J Oral Maxillofac Surg. 2013;42:1481-1487. doi:10.1016/j.ijom.2013.06.011.

103. Lechner J, Schuett S, von Baehr V. Aseptic-avascular osteonecrosis: local "silent inflammation" in the jawbone and RANTES/ CCL5 overexpression. Clin Cosmet Investig Dent. 2017;9:99-109. doi:10.2147/CCIDE.S149545.

104. Ruggiero SL, Fantasia J, Carlson E. Bisphosphonate-related osteonecrosis of the jaw: background and guidelines for diagnosis, staging and management. Oral Surg Oral Med Oral Pathol Oral Radiol Endodontol. 2006;102:433-441. doi:10.1016/j. tripleo.2006.06.004.

105. Mawardi H, Treister N, Richardson P, et al. Sinus tracts — an early sign of bisphosphonate-associated osteonecrosis of the jaws? J Oral Maxillofacial Surg. 2009;67:593-601. doi:10.1016/j. joms.2008.09.031.
106. Bagán J, Blade J, Cozar JM, et al. Recommendations for the prevention, diagnosis, and treatment of osteonecrosis of the jaw (ONJ) in cancer patients treated with bisphosphonates. Med Oral Patol Oral Cir Bucal. 2007;12:E336-40.

107. Cossío PI, Macián AC, Pérez Ceballos JL, Nicas JP, Gutiérrez Pérez JL. Bisphosphonate-related osteonecrosis of the jaw in patients with multiple myeloma. Med Oral Patol Oral Cir Bucal. 2008;13:E52-7.

108. Yip RML. Bisphosphonates and osteonecrosis of the jaw. Hong Kong Bull Rheum Dis. 2008;8:19-25.

109. Ruggiero SL, Drew SJ. Osteonecrosis of the Jaws and Bisphosphonate Therapy. J Dent Res. 2007;86:1013-1021. doi:10.1177/154405910708601101.

110. Dimopoulos MA, Kastritis E, Bamia C, et al. Reduction of osteonecrosis of the jaw (ONJ) after implementation of preventive measures in patients with multiple myeloma treated with zoledronic acid. Ann Oncol. 2009;20:117-120. doi:10.1093/ annonc/mdn554.

111. Bramati A, Girelli S, Farina G, et al. Prospective, mono-institutional study of the impact of a systematic prevention program on incidence and outcome of osteonecrosis of the jaw in patients treated with bisphosphonates for bone metastases. $J$ Bone Miner Metab. 2015;33:119-124. doi:10.1007/s00774-014-0566-x.

112. Hjørting-Hansen E. Decortication in treatment of osteomyelitis of the mandible. Oral Surg Oral Med Oral Pathol. 1970;29:641-655. doi:10.1016/0030-4220(70)90259-8.

\section{Publish your work in this journal}

Clinical, Cosmetic and Investigational Dentistry is an international, peer-reviewed, open access, online journal focusing on the latest clinical and experimental research in dentistry with specific emphasis on cosmetic interventions. Innovative developments in dental materials, techniques and devices that improve outcomes and patient satisfaction and preference will be highlighted. The manuscript management system is completely online and includes a very quick and fair peer-review system, which is all easy to use. Visit http://www.dovepress.com/testimonials.php to read real quotes from published authors. 